Int. J. Dev. Biol. 58: 841-849 (2014)

doi: $10.1387 / \mathrm{ijdb} .140270 \mathrm{sk}$

\title{
Comparative expression analysis of cysteine-rich intestinal protein family members crip1, 2 and 3 during Xenopus laevis embryogenesis
}

\author{
ANNEMARIE HEMPEL ${ }^{1,2}$ and SUSANNE J. KÜHL*,1 \\ ${ }^{1}$ Institute for Biochemistry and Molecular Biology and \\ 2 International Graduate School in Molecular Medicine UIm, Ulm University, UIm, Germany
}

\begin{abstract}
Members of the cysteine-rich intestinal protein (Crip) family belong to the group 2 LIM proteins. Crip proteins are widely expressed in adult mammals but their expression profile and function during embryonic development are still mostly unknown. In this study, we have described for the first time the spatio-temporal expression pattern of the three family members crip1, crip2 and crip3 during Xenopus laevis embryogenesis by RT-PCR and whole mount in situ hybridization approaches. We observed that all three genes are expressed in the pronephros, branchial arches and the eye. Furthermore, crip1 transcripts could be visualized in the developing cranial ganglia and neural tube. In contrast, crip2 could be detected in the cardiovascular system, the brain and the neural tube while crip3 was expressed in the cranial ganglions and the heart. Based on these findings, we suggest that each crip family member may play an important role during embryonic development.
\end{abstract}

KEY WORDS: Xenopus laevis, cystein-rich protein, crip1-3, LIM

The first cysteine-rich intestinal protein (CRIP) was discovered as a marker for the suckling-to-weaning transition in the rodent intestine by Birkenmeier and Gordon (Birkenmeier and Gordon, 1986). Among the original names for the different Crip proteins was CRP2 (now Crip2) (Okano et al., 1993), which could easily be mistaken for a cysteine and glycine-rich protein (now classified as CSRP). Both subgroups, Crip and CSRP, belong to the group 2 LIM proteins and consist of three distinct representatives (Birkenmeier and Gordon, 1986, Hempe and Cousins, 1991, van Ham et al., 2003). While Crip1 contains only one single LIM domain, Crip2 and Crip3 carry two of them (Kirchner et al., 2001, Nalik et al., 1989, Wang et al., 1992). Such differences could be the result of DNA duplication events (Nalik et al., 1989). The LIM domain is a conserved cysteine-histidine-rich sequence with a double zinc-finger with the consensus sequence $\left(\mathrm{CX}_{2} \mathrm{CX}_{17} \mathrm{HX}_{2} \mathrm{C}\right)-\mathrm{X}_{2}-\left(\mathrm{CX}_{2} \mathrm{CX}_{17} \mathrm{CX}_{3} \mathrm{C}\right)$ (Bach, 2000, Liebhaber et al., 1990). LIM domains are postulated to promote protein-protein interactions exemplified by the interaction between the LIM domain of Crip2 and the PDZ domain IV of PTP-BL (protein tyrosine phosphatase PTP-BL five) (Bach, 2000, van Ham et al., 2003). Furthermore, the LIM domain is known to bind zinc that probably accounts for the zinc-binding properties of
Crip1 reported by Hempe and Cousins (Hempe and Cousins, 1991, Hempe and Cousins, 1992). In addition, the zinc-dependent metalloprotease ADAM19 facilitate Crip2 secretion (Tanabe et al., 2010).

In adult mammals, all cripgenes exhibit a wide tissue distribution, which might indicate essential roles in diverse cellular functions (Birkenmeier and Gordon, 1986, Casrouge et al., 2004, Chung et al., 2011, Hallquist et al., 1996, Karim et al., 1996, Kirchner et al., 2001, Levenson et al., 1993, Nalik et al., 1989, Okano et al., 1993, Tsui et al., 1994, van Ham et al., 2003, Wang et al., 1992, Yu et al., 2002). The different crip members have been linked to tissue differentiation and remodelling, immune response as well as suppression of angiogenesis and tumorigenesis (Chung et al., 2011, Davis et al., 1998, Hallquist et al., 1996, Khoo et al., 1996, Lanningham-Foster et al., 2002, Wei et al., 2011).

However, little is known about the expression profiles or functions of the crip family members during early embryogenesis in

Abbreviations used in this paper: crip, cysteine-rich intestinal protein; LIM, Lin 1 1, Isl-1 and Mec-3; RT-PCR, reverse transcription polymerase chain reaction; WMISH, whole-mount in situ hybridization; X. laevis/tropicalis, Xenopus laevis/tropicalis.

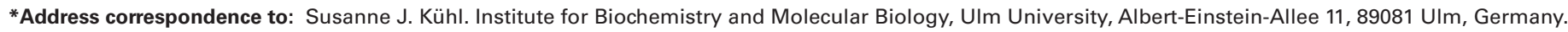
Tel: ++49-731-500-23283. Fax: ++49-731-500-23277. E-Mail: susanne.kuehl@uni-ulm.de
}

Supplementary Material (four figures) for this paper is available at: http://dx.doi.org/10.1387/ijdb.140270sk

Accepted: 19 December 2014.

ISSN: Online 1696-3547, Print 0214-6282 
A

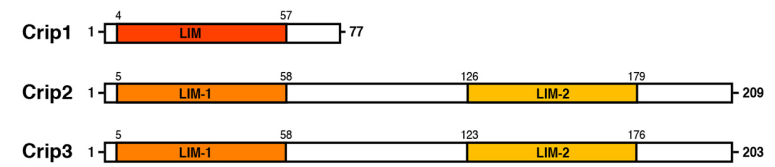

B

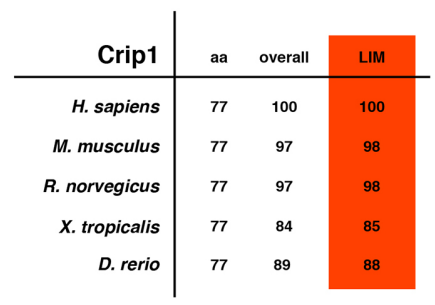

C

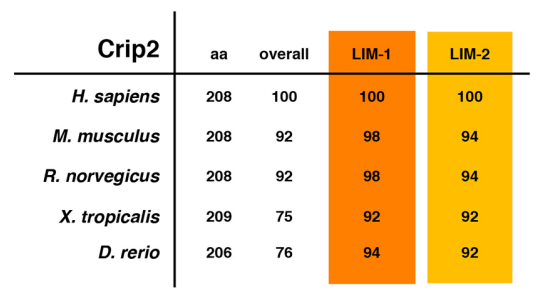

D
E

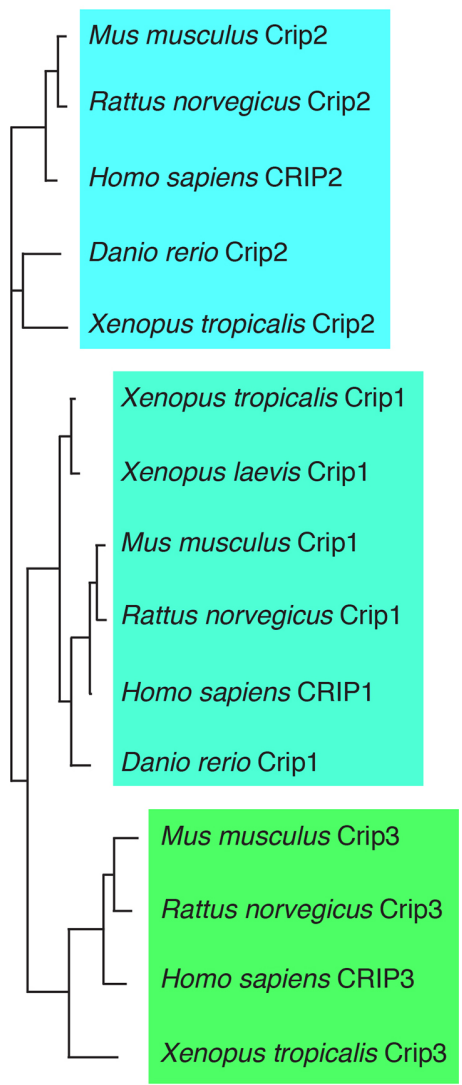

Fig. 1. Crip1, Crip2 and Crip3 in Xenopus. (A) Schematic representation of X. tropicalis Crip1, Crip2 and Crip3 protein domains. Crip1 contains one LIM domain, while Crip2 and Crip3 have two (LIM-1 and -2) each. (B-D) Homology of the amino acid sequences of the full length (overall) and individual LIM domains of the Crip proteins among different species. Numbers represent similarities of the indicated species in percentage compared to Homo sapiens. (E) Phylogenetic tree for the Crip sequences whose primary amino acid sequence alignment is shown in (A). aa, amino acid length in numbers; CRIP, cysteine-rich intestinal protein; LIM, Lin11, IsI-1 and Mec-3.

any organism. In this study, we present the specific expression pattern of crip1, crip2 and crip3 throughout early Xenopus laevis embryogenesis, which are fundamental information for future functional analyses. We thus provide in this paper the first comparative embryonic expression analyses of all three crip genes in a vertebrate organism.

\section{Results and Discussion}

\section{Xenopus cysteine-rich protein family members}

So far no expression or functional data have been reported about the different members of the cysteine-rich protein family in Xenopus. For an initial analysis of crip genes in Xenopus, we relied on publicly available Xenopus laevis/tropicalis sequences. The predicted protein sequences of each Crip family member were highly conserved across species (Fig. 1 B-D). While Crip1 contained only one LIM-domain, both Crip2 and Crip3 contained two LIM domains (LIM-1 and -2) (Fig. 1A), all of which were highly conserved among different species (Fig. 1 B-D). Nevertheless, all three Crip family members are closely related as phylogenetic analysis showed (Fig. 1E). Furthermore, synteny analyses showed that crip1 and crip2 are neighbouring genes. Their gene loci and their neighbouring genes are highly conserved between Homo sapiens, Mus musculus, Rattus norvegicus and Xenopus tropicalis (Fig. 2A). Surprisingly, in the Xenopus tropicalis genome, the genes pacs2, mta1 and crip1 had been inverted compared to the genomes of human, mouse and rat for unknown reasons. The gene loci of crip3 and its neighbouring genes are highly conserved between Homo sapiens, Mus musculus and Rattus norvegicus as well (Fig. 2B). The available Xenopus tropicalis genomic region covering crip3 (Gene ID 548528) is too short for a detailed analysis and can therefore not be compared with the gene loci of other organisms. The preserved protein structures and gene localizations of the individual Crip family members suggest a conserved expression as well as conserved function of the crip genes across species.

To investigate the temporal expression pattern of crip 1-3 during Xenopus laevis embryogenesis, semi-quantitative reverse transcription polymerase chain reaction (RT-PCR) experiments using Xenopus laevis specific crip1-3 primer pairs (Suppl. Figs. 1-3) were performed. Whereas crip1 and crip2 transcripts were first detected during gastrulation as early as stage 10 and 12.5 
respectively, crip3 was maternally supplied and continuously expressed throughout early embryogenesis (Fig. 3).

We next analyzed the spatio-temporal expression of all three crip family members during Xenopus laevis embryogenesis by whole-mount in situ hybridization (WMISH). For further tissuespecific analysis, vibratome sections using stained embryos were performed. To examine the expression profiles of all three crip family members, we cloned Xenopus laevis specific cDNA fragments with the length of $550 \mathrm{bp}$ (crip1), $539 \mathrm{bp}$ (crip2) and 492 bp (crip3) and generated antisense DIG-labelled RNA probes (Suppl. Figs. 1-3). To sow the specificity of these probes, we performed a dot blot indicating the usability of the signed probes (Suppl. Figure 4).

\section{Expression of crip1 during Xenopus embryogenesis}

The first tissue-specific expression of crip1 was detected during gastrulation (data not shown) and became manifested at stage 13 in the anterior neural plate (Fig. 4B) being in line with the RT-PCR data. At stage 20, crip1 was expressed in the developing neural tissue (Fig. 4C). At stage 25, crip1 transcripts were detected at the dorsal side of the embryo and in the migrating cranial neural crest cells (Fig. 4D). In early tailbud stages, crip1 was strongly expressed in the neural crest derived part of the second and third branchial arches and at the dorsal aorta and in the blood islands as well (Fig. 4 E-F, I; Fig. 5 G-J,T). Furthermore, crip 1 was clearly visible in the neural roof plate and the ventral region of the neural tube at stage 33 (Fig. 5K) and at the neural floor plate at stage 38

A

Homo sapiens

(chromosome 14)

ATP5G1P1

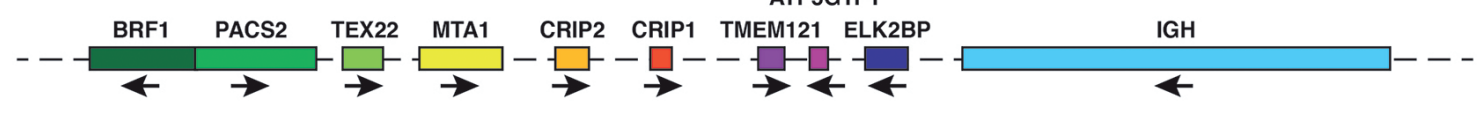

Mus musculus

(chromosome 12)

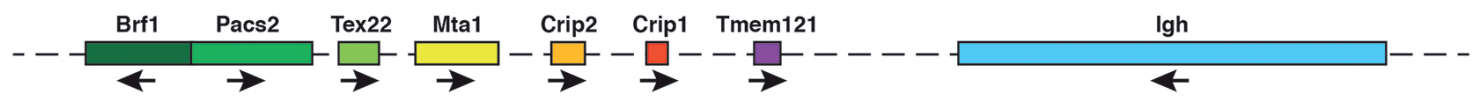

Rattus norvegicus (chromosome 6)

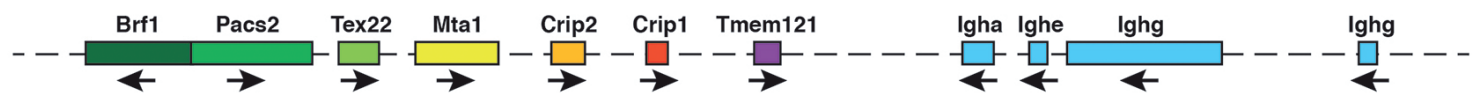

Xenopus tropicalis (unplaced scaffold)

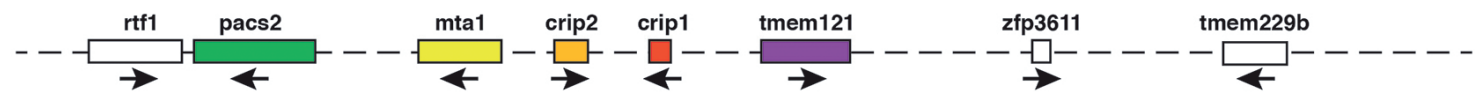

\section{B}

Homo sapiens

(chromosome 6)

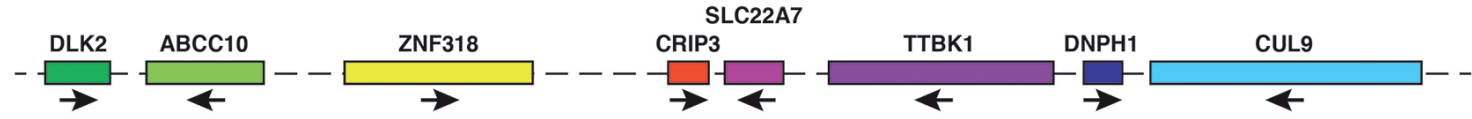

Mus musculus

(chromosome 17)

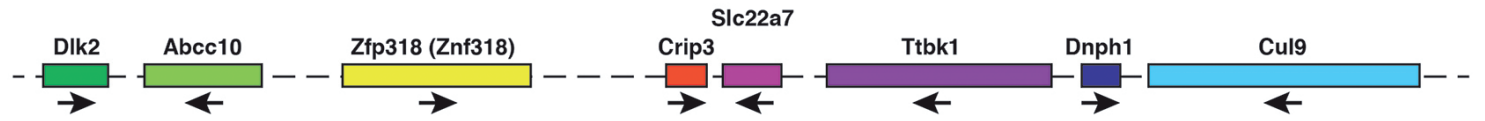

Rattus norvegicus (chromosome 9)

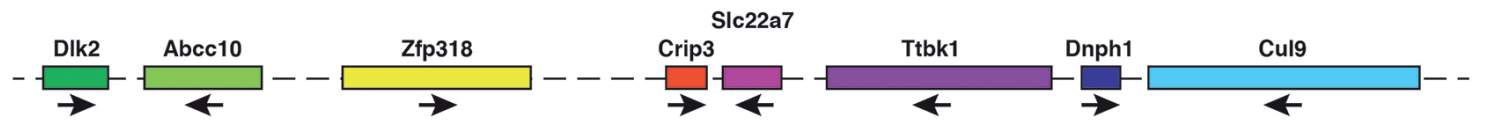

Xenopus tropicalis (unplaced scaffold)

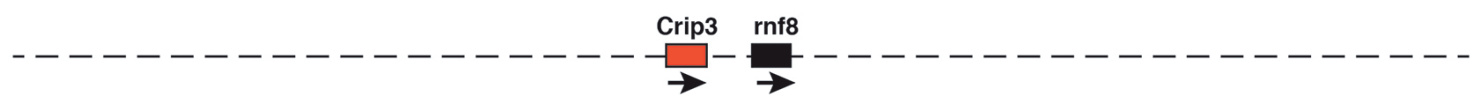

Fig. 2. Synteny analyses of the crip family members in Homo sapiens, Mus musculus, Rattus norvegicus, Xenopus tropicalis and Danio rerio. (A) The schematic overview shows the comparison of the crip1 and crip2 genes and their neighbouring gene loci in $\mathrm{H}$. sapiens (chromosome 14), $\mathrm{M}$. musculus (chromosome 12), R. norvegicus (chromosome 6) and X. tropicalis (unplaced scaffold). (B) The schematic overview shows the comparison of the crip3 gene and its neighbouring gene loci in $\mathrm{H}$. sapiens (chromosome 6), M. musculus (chromosome 17), R. norvegicus (chromosome 9) and X. tropicalis (unplaced scaffold). The gene length and distances between them are not drawn to scale. Conserved genes are indicated by the same color code and non-conserved genes by white boxes. The orientation of the genes open reading frames are depicted by black arrows. Abcc 10 ATP-binding cassette sub-family C (CFTR/MRP) member 10, asxl2 additional sex combs like 2 (Drosophila), ATP5G1P1 ATP synthase, H+ transporting, mitochondrial Fo complex, subunit C1 (subunit 9) pseudogene 1, BRF1 BRF1 RNA polymerase III transcription initiation factor 90 kDa subunit, CUL9 cullin 9, DLK2 delta-like 2 homolog (Drosophila), DNPH1 2'-deoxynucleoside 5'-phosphate N-hydrolase 1, dtnbb dystrobrevin beta b, ELK2BP ELK2B member of ETS oncogene family pseudogene, hadhab hydroxyacyl-CoA dehydrogenase/3-ketoacyl-CoA thiolase/enoyl-CoA hydratase (trifunctional protein) alpha subunit b, IGH immunoglobulin heavy locus/immunoglobulin heavy chain complex, Igha immunoglobulin heavy chain alpha, Ighe immunoglobulin heavy chain (epsilon polypeptide), Ighg immunoglobulin heavy chain (gamma polypeptide), kif3cb kinesin family member 3Cb, mta1 metastasis associated 1, pacs2 phosphofurin acidic cluster sorting protein 2, ptgr2 prostaglandin reductase 2, rnf8 ring finger protein 8, E3 ubiquitin protein ligase, rtf1 Rtf1 Paf1/RNA polymerase I/ complex component homolog, SLC22A7 solute carrier family 22 (organic anion transporter) member 7, slc25a21 solute carrier family 25 (mitochondrial oxodicarboxylate carrier) member 21, slc30a1b solute carrier family 30 (zinc transporter) member $1 \mathrm{~b}$, TEX22 testis expressed 22, tmem121 transmembrane protein 121, tmem229b transmembrane protein 229B, tmem62 transmembrane protein 62, TTBK1 tau tubulin kinase 1 , zfp36l1a zinc finger protein 36 C3H type-like 1a, ZNF318/Zfp318 zinc finger protein 318. 


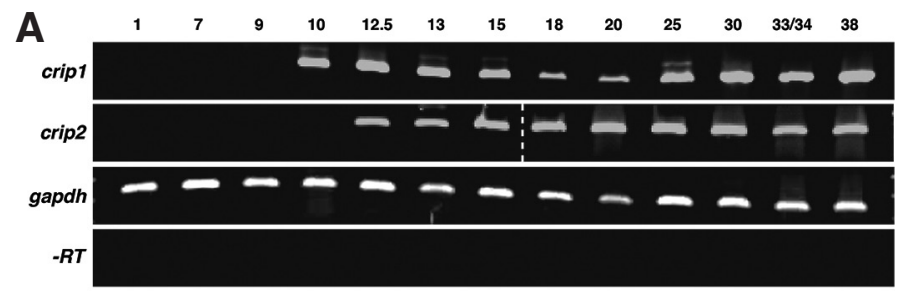

B

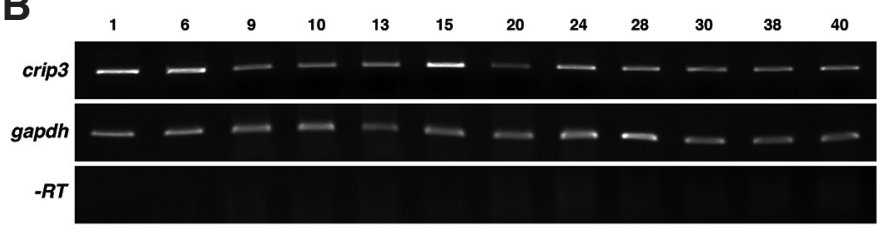

Fig. 3. Temporal expression patterns of crip1-3 during Xenopus laevis embryogenesis analysed by semi-quantitative RT-PCR approaches with cDNA templates of the indicated stages. As loading control gapdh (glycerinaldehyde-3-phosphate dehydrogenase) and as negative controls-RT (reverse transcriptase) reactions lacking the enzyme reverse transcriptase were used. (A) Crip1 and crip2 expression were first detected during gastrulation at stage 10 and 12.5 respectively and continuously expressed till stage 38. (B) In contrast crip3 transcripts were maternally supplied and continuously expressed till stage 40.
(Fig. 5T). At stage 38 and 41, crip 1 was expressed in the anlagen of the developing cartilage structures including the quadrate cartilage, Meckel's cartilage, ceratobranchial cartilage and ceratohyal cartilage as well as the branchial arches (Fig. $4 \mathrm{G}-\mathrm{H}$; Fig. $5 \mathrm{M}-\mathrm{O}$ ). Additionally, crip1 was found in the sensory layer of the epidermis and the ganglion cell layer of the retina (Fig. $5 \mathrm{~N}, \mathrm{~S}$ ). Moreover, a specific crip1 expression could be detected in the cardiac arteries, the second heart field and the ventral aorta (Fig. 4 J-K; Fig. 5 $\mathrm{M}, \mathrm{P}-\mathrm{R})$. These results are in line with data by others demonstrating CRIP1 mRNA expression in fetal rat and human hearts (Tsui et al., 1994). Crip1 transcripts were also detected in the tubules of the developing pronephros (Fig. 5U) and lung (Fig 5V). Not much is known about crip1 expression during early embryogenesis in other vertebrate species. Further studies will be required to determine whether crip1 expression is conserved across species.

\section{Expression of crip2 during Xenopus embryogenesis}

The tissue-specific expression of crip2 started during gastrulation (data not shown) what is in agreement with RT-PCR results. At stage 13, crip2 was strongly expressed in the anterior neural plate (Fig. 6A). At stage 23, crip2 was expressed in the anterior neural tissue (Fig. 6B) and at stage 25 at the dorsal side of the embryo and the migrating neural crest cells (Fig. 6C). In tailbud stages,

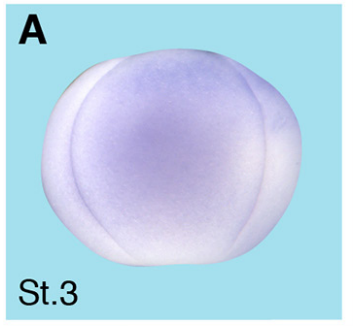

B

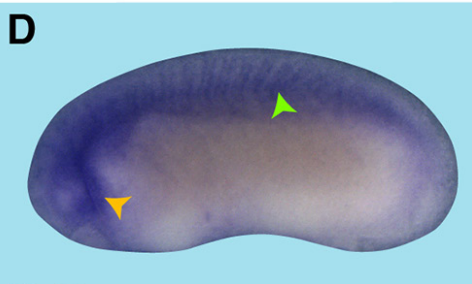

St.25
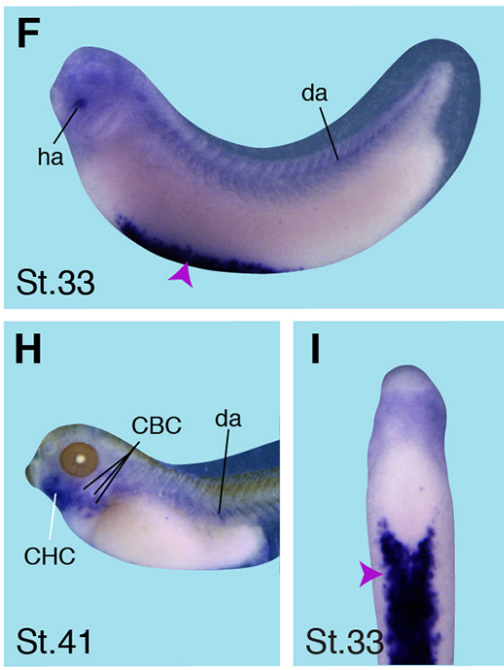

I

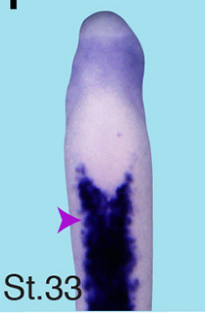

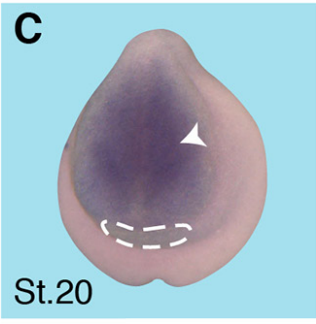
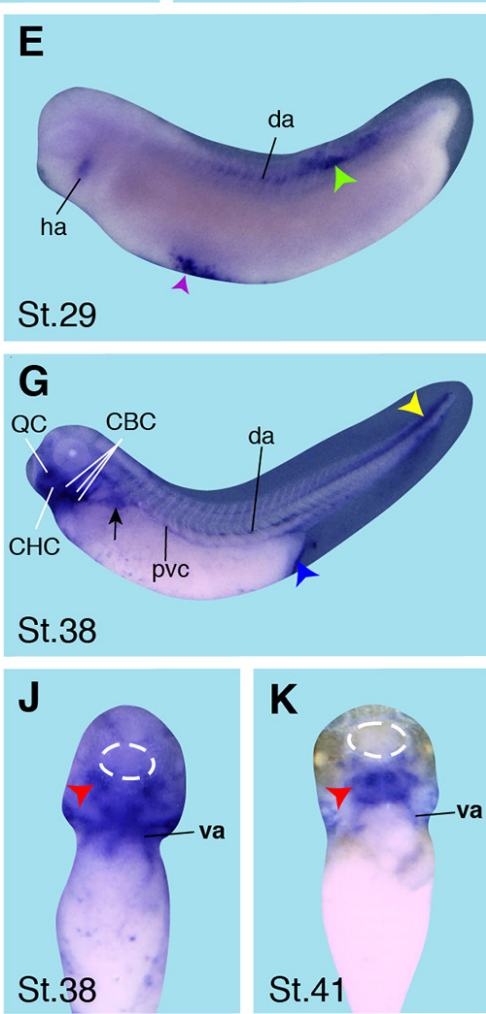

Fig. 4. Crip1 spatial expression pattern during $X$. laevis embryogenesis. Embryonic stages are indicated in each panel. The white dashed circles depict the cement gland. (A) At stage 3, embryos were negative for crip1 expression (lateral view). (B) Anterior view of a stage 13 embryo. Crip1 was expressed in the anterior neural plate (black arrowhead). (C) The anterior view of a stage 20 embryo shows crip1 expression of in the anterior neural tissue (white arrowhead). (D-H) Lateral views with anterior to the left. (I-K) Ventral views with anterior to the top. (D) At stage 25 crip1 transcripts were detected in the migrating cranial neural crest cells (orange arrowhead) and at the dorsal side of the embryo (green arrowhead). (E-F, I) Crip1 was expressed in the hyoid arch (ha), in the dorsal aorta (da) with a stronger expression in the posterior part (green arrowhead) and in the ventral blood islands (violet arrowhead). (G-H) In later stages crip1 transcripts were strongly detected in the head mesenchyme, namely the quadrate cartilage (QC), ceratobranchial cartilage (CBC), and ceratohyal cartilage (CHC) as well as. Crip1 transcripts were in the dorsal aorta (da) detected. Furthermore, crip1 was expressed in the pronephric tubule convolute (black arrow) and in the posterior cardinal vein (pcv). The stomadeum including the region where the cloaca will form (blue arrowhead) as well as the tip of the tail (yellow arrowhead) showed a strong crip1 expression, too. (J-K) Also the second heart field (red arrowhead) and ventral aorta (va) were positive for crip1. 

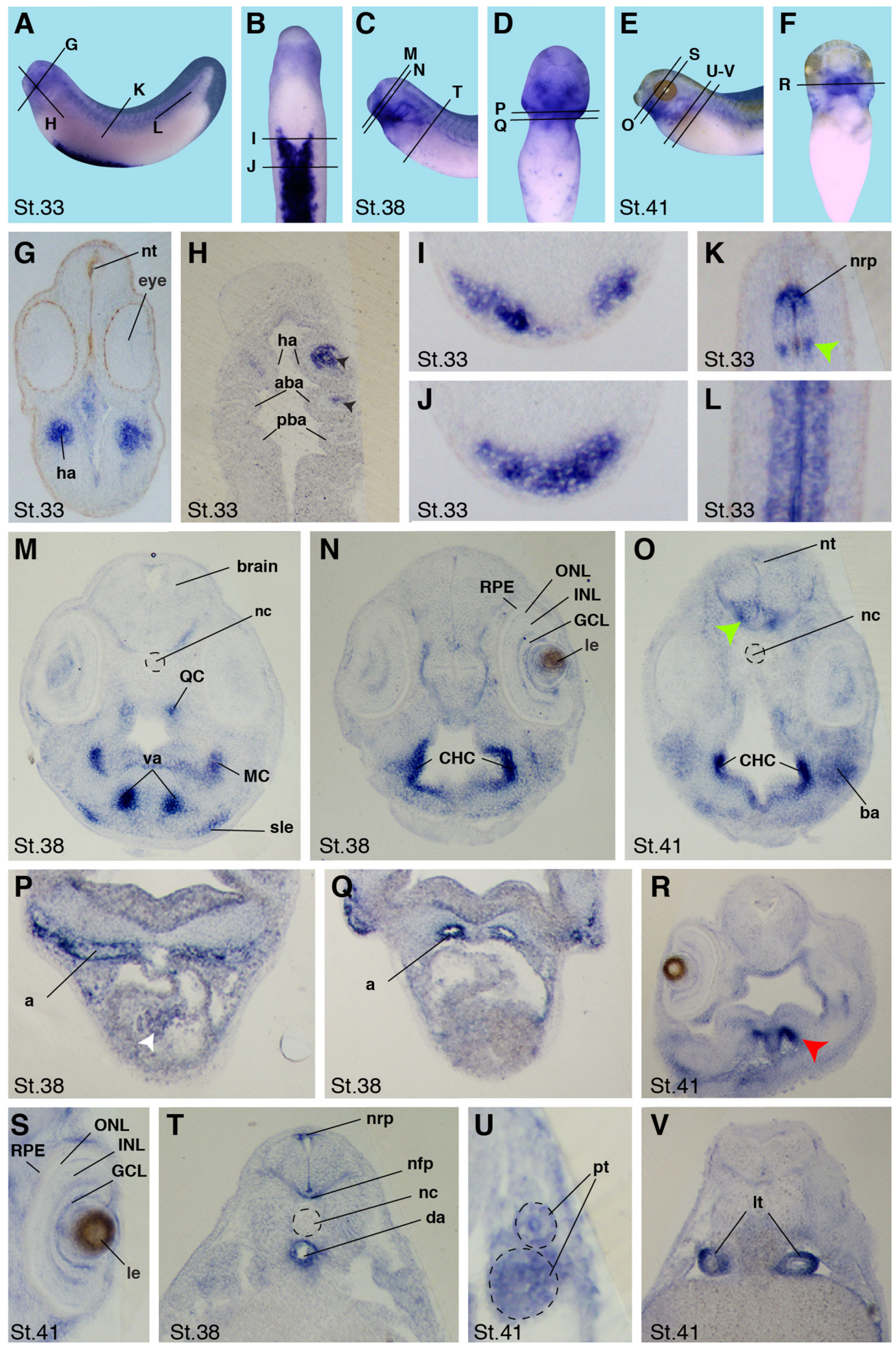

Fig. 5. Tissue specific expression of crip 1 in Xenopus embryos stage 33, 38 and 41. $(\mathbf{A}, \mathbf{C}, \mathrm{E})$ Lateral views with anterior to the left. (B,D,E) Ventral views with anterior to the top. Black lines indicate level of sections shown in G-V. (G,I-K,M-V) Transversal sections with the dorsal side to the top. $(\mathbf{H}, \mathbf{L})$ Horizontal sections with anterior to the top. The notochord (nc) and pronephric tubules (pt) are depicted by dashed circles, respectively (M,O,T,U). (G-H ) At stage 33 crip1 transcripts were detected in the neural crest derived part of the second and third branchial arches namely the hyoid arch (ha) and the anterior branchial arch (aba) but not in the posterior third branchial arch (pba) (black arrowheads). (I-L) Furthermore, crip1 was strongly expressed in the blood islands (I-J) and neural roof plate (nrp) and a specific ventral region of the neural tube (green arrowhead) (K-L). (M-O) Later, crip1 was strongly expressed in the ventral aorta (va), in the sensory layer of the epidermis (sle) and the cranial cartilage structures as indicated: quadrate cartilages (QC), Meckel's cartilages (MC), ceratohyal cartilages (CHC) as well as in the branchial arches (ba).

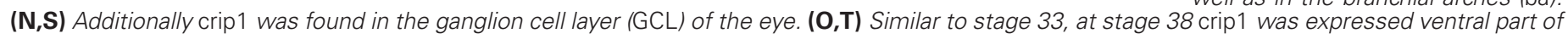
the neural tube (green arrowhead), the neural roof plate (nrp) and in the neural floor plate (nfp). (T) Furthermore, crip1 transcripts were detected in the surrounding layer of the dorsal aorta (da). (P-R) Sections through the heart region revealed crip1 expression in the arteries (a), at stage 38 weakly in the endocardium (white arrowhead) and at stage 41 in the second heart field (red arrowheads). (U-V) At stage 41 crip1 was expressed in the pronephric tubules (pt) and in the lung tubes (t). le, lens; INL and ONL, inner and outer nuclear layer; RPE, retinal pigmented epithelium. 

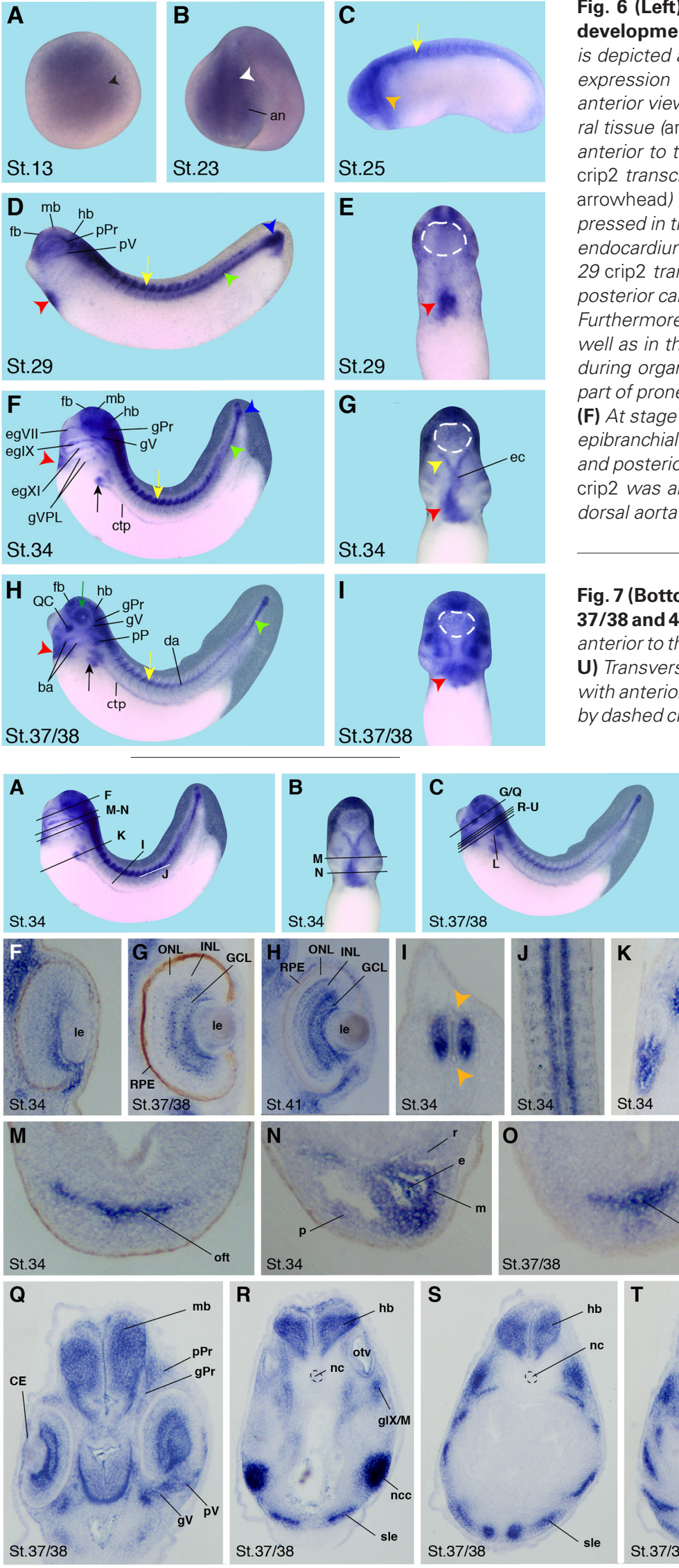
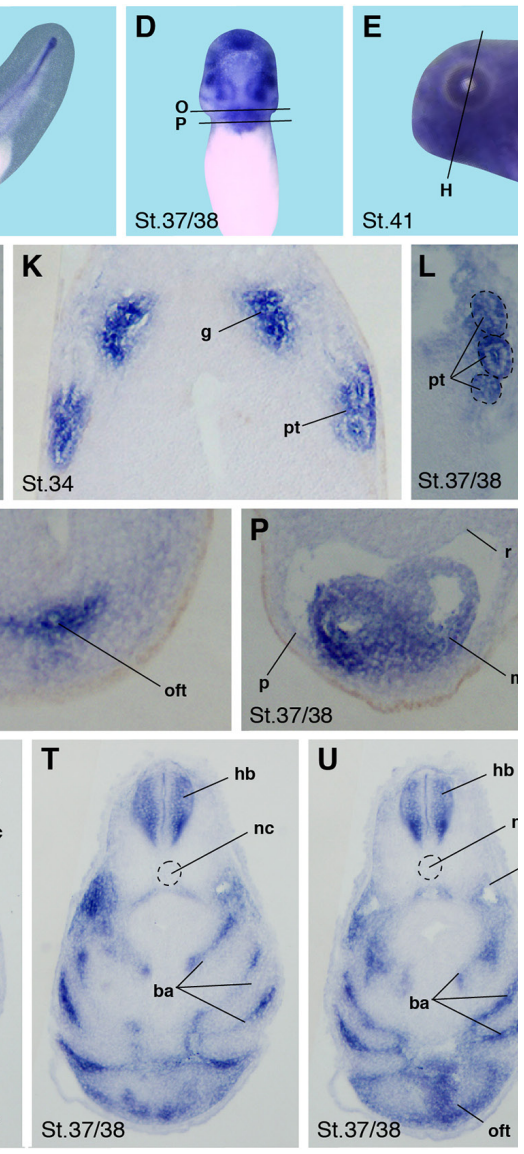

Fig. 6 (Left). Spatial expression pattern of crip2 during $X$. laevis embryonic development. Embryonic stages are indicated in each panel. The cement gland is depicted as white dashed circles. (A) Animal view of a stage 13 embryo. Crip2 ral tissue (an) and the neural tube (white arrowhead). (C-D,F,H) Lateral views with crip2 transcriptst. (E,G,I) Ventral views with anterior to the top. (C) At stage 25 arrowhead) and the dorsal side of the embryo (yellow arrow). (D-I) Crip2 was expressed in the cardiac tissue especially of the first heart field (red arrowheads), the endocardium (ec) and the cardiac vascular nerves (yellow arrowhead). (D) At stage posterior cardinal vein (green arrowhead) and at the tip of the tail (blue arrowhead). (hermore, crip2 was expressed in the fore-, mid- and hindbrain ( $\mathrm{fb}, \mathrm{mb}, \mathrm{hb}$ ) as (F) At pronephros (black arrow) and the connecting tubule of the pronephros (ctp). epibranchial ganglia egVII, egIX and egXI and the cells that contribute to the vagal and posterior lateral line ganglion (gVPL) were positive for crip2. (H) At stage 37/38 crip2 was also expressed the quadrate cartilages (OC), branchial arches (ba) and

Fig. 7 (Bottom). Crip2 tissue specific expression in Xenopus embryos stage 34, $\mathbf{3 7 / 3 8}$ and 41. (A,C,E) Lateral views with anterior to the left. (B,D) Ventral views with with anterior to the top. The notochord (nc) and pronephric tubules (pt) are depicted by dashed circles, respectively (L,R-U). (F-H) During Xenopus embryogenesis crip2 was expressed in the developing eye, more precisely the ganglion cell layer (GCL). In contrast, no expression was detected in the lens (le), the inner and outer nuclear layer (INL, ONL) or the retinal pigmented epithelium (RPE). (I,J) At stage 34 crip2 was found in the neural tube except at the most dorsal and ventral parts (orange arrowheads). $(\mathbf{K}, \mathbf{L})$ Furthermore, crip2 expression was detected in the glomerulus (g) and the specific pronephric tubules (pt). (M-P) Cardiac sections at stage 34 and $37 / 38$ revealed crip2 expression in the outflow tract (oft), the pericardial roof (r) as well as the myo- and endocardium ( $\mathrm{m}, \mathrm{e}$ ) of the developing heart, but not the pericardium (p). (Q-U) Crip2 was expressed in various tissue of the brain, predominantly in the mid-and hindbrain (mb, hb). The ganglia and placodes of the profundal (gPr, $\mathrm{pPr})$ and trigeminus (gV, $\mathrm{pV}$ ) show distinct crip2 expression as well as the cornea epithelium (CE) (Q). (R-I) Consecutive transversal sections at the level of the otic vesicle (otv) showed crip2 transcripts in the sensory layer of epidermis (sle), neural crest cells (ncc), the fused ganglia of the glossopharyngeal and middle lateral line nerves (gIX/M) and the branchial arches (ba). 
crip2 transcripts were detected in various parts of the brain (Fig. $7 \mathrm{Q}-\mathrm{U}$ ) as well as in the posterior neural tube (Fig. 7I). Note, that in the neural tube, differentiated neurons were crip2positive whereas neural stem cells located in the centre of the neural tube were negative for crip2. The facial epibranchial ganglia egVII, egIX and egXI, the cells that contribute to the vagal and posterior lateral line ganglion as well as the placodes and ganglia of the profundal and trigeminus nerve also showed distinct crip2 expression at sages 34 (Fig. 6 D,F). Additionally, crip2 was expressed in the sensory layer of the epidermis, neural crest cells, the fused ganglia of the glossopharyngeal and middle lateral line nerves (Fig. 6F; Fig. 7Q-S) and the branchial arches (Fig. 6H; Fig. $7 \mathrm{~T}-\mathrm{U}$ ). In the ganglion cell layer of the eye, crip2 transcripts were detected as well (Fig. 7 F-H). Furthermore, crip2 expression was visualized in the developing pronephros (Fig. 6 F,H; Fig. 7 K-L) and in the pericardial roof, the myo-and endocardium of the developing heart (Fig. 6 D-I; Fig. 7 M-P).

The spatio-temporal expression of Crip2 during embryogenesis was also described in more detail in mice and zebrafish (Sun et al., 2008, Wei et al., 2011, Yu et al., 2002). Crip2 is detected in pre-streak embryo, up-regulated with the onset of gastrulation and shows an abundant expression throughout the developing heart which is consistent with our expression study. Later during murine embryogenesis, Crip2 is expressed in the heart primordial (E7.5), heart tube (E8.5) and strongly in the myo- and endocardium as well as the coronary vascular endothelial cells in the atrium and ventricle of embryonic (E9.5-15.5) and adult mouse hearts. Again, this is in agreement with crip2 expression in Xenpous. Additionally, murine Crip2 was detected in lymphatic endothelial cells, in dorsal root ganglia and around the spinal cord, the neural tube including the brain, lungs, pelvic ganglia and mesenchyme of the lower urinary tract, but not in the kidney (Wei et al., 2011, Wiese et al., 2012, Yu et al., 2002, Zhang et al., 2005). In zebrafish, crip2 transcript were detected the earliest in the premigratory neural crest cells in rhombomere 6 of the neural tube, in the cardiac progenitor cells in anterior lateral plate mesoderm and mesoendodermal cells in the primary heart field (6- to 20-somite stage). Later during zebrafish embryogenesis, crip2 was expressed in the heart tube, ventricular cardiomyocytes and aortic vessels in pharyngeal arches 3-6 (24-36 hpf) (Sun et al., 2008). Hence, crip2 was recently used as cardiac neural crest cell marker (Wang et al., 2013). Collectively, these data indicate a conserved expression of crip2 across species.

\section{Expression of crip3 during Xenopus embryogenesis}

Like in the RT-PCR experiments, crip3 transcripts could be detected early on by WMISH approaches. At stage 3, crip3 was visualized in the animal half of the embryo (Fig. 8A). At stage 13,

\section{St.41}
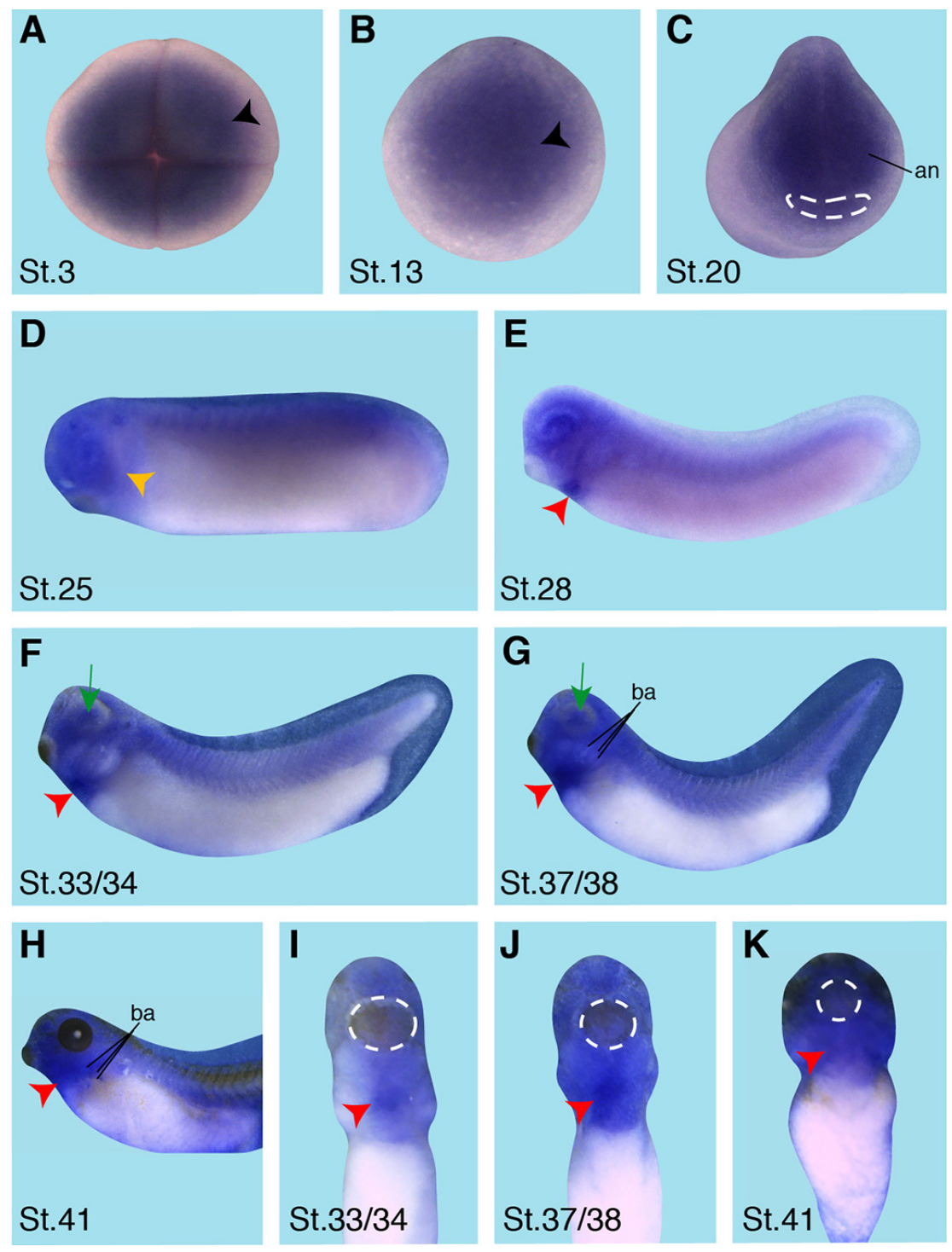

Fig. 8. Spatial expression of crip3 during $\boldsymbol{X}$. laevis embryogenesis. Embryonic stages are indicated in each panel. The white dashed circles depict the cement gland. (A) Animal view. Crip3 expression was detected at the animal half at 4-cell stage (black arrowhead). (B) Crip3 is expressed in the anterior neural plate. (C) The anterior view of a stage 20 embryo showed crip3 expression in the anterior neural tissue (an). (D-H) Lateral views with anterior to the left. (I-K) Ventral views with anterior to the top. (D-H) At stage 25 and 29 crip3 was expressed in the migrating neural crest cells (orange arrowhead in $(D, E)$ and at later stages in the branchial arches (ba, G,H). (F,G) During organogenesis a very weak crip3 signal was seen in the dorsal side of the embryo (green arrowheads). (E-K) Furthermore, during Xenopus embryogenesis crip3 was detected in the developing eye (green arrow) and cardiac tissue (red arrowheads).

crip3 was expressed in the anterior neural plate (Fig. 8B) and later in the anterior neural tissue (Fig. 8C). During stage 33/34 crip3 was weakly expressed in a subpopulation of differentiated neurons in the midbrain (Fig. 9B). In later tailbud stages, crip3 was strongly expressed in the branchial arches (Fig. 9N) as well as in the peri-, myo- and endocardium and the pericardial roof of the developing heart (Fig. $8 \mathrm{E}-\mathrm{K}$; Fig. $9 \mathrm{H}-\mathrm{I}$ ). A very faint expression was also detected in the developing pronephros and in the anlage of the ceratohyal cartilage (Fig. 9 G,M). Furthermore, crip3 was located in the cornea epithelium of the developing eye at stage 33/34 and 

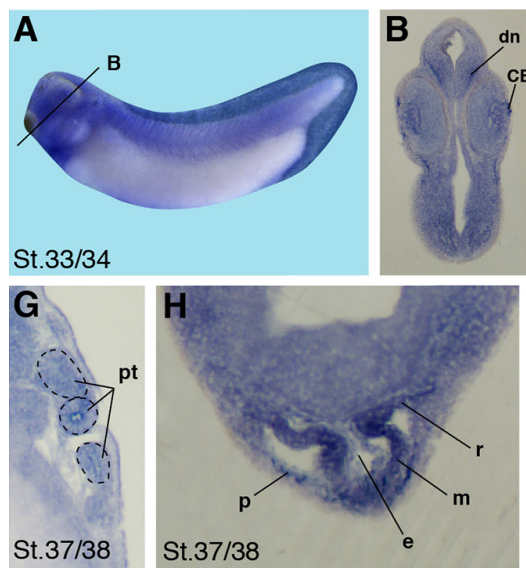
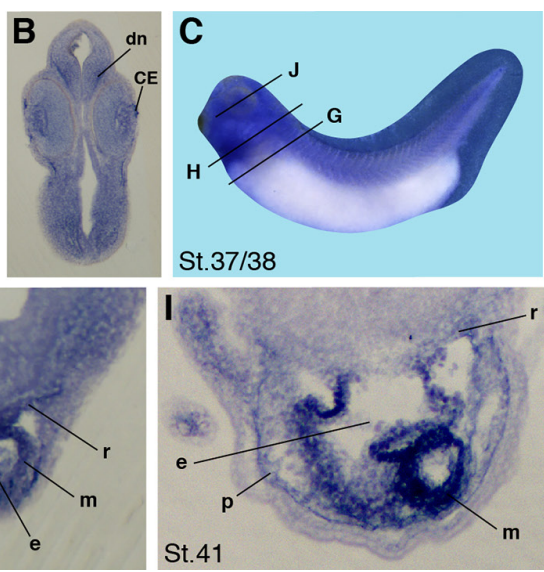

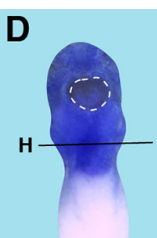

St.37/38

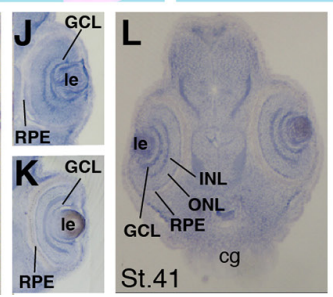

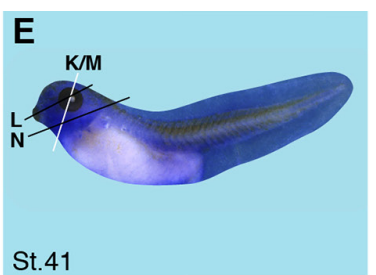
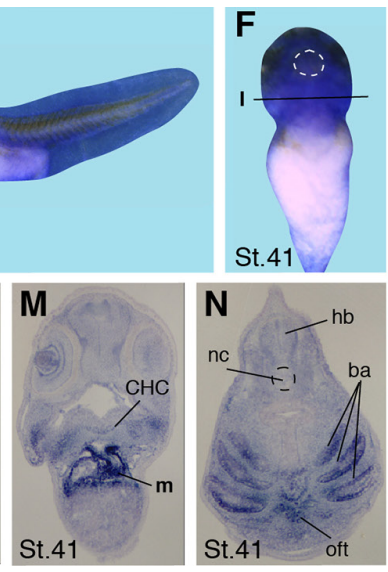

Fig. 9. Tissue specific expression of crip3 in Xenopus embryos stage 33/34, 38 and 41. (A,C,E) Lateral views with anterior to the left. (D,F) Ventral views with anterior to the top. White dotted circles depict the cement gland. (B, G-N) Transversal vibratome sections through different regions of the embryos with the dorsal to the top as indicated by the lines shown in A,C-F. The pronephric tubules (pt) and notochord (nc) are depicted by dashed circles, respectively $(\mathbf{G}, \mathbf{N})$. (B, G) Crip3 transcripts were weakly expressed in the differentiated neurons (dn, B) and in the pronephric tubules (pt, G). (H-I,M-N) The strongest expression of crip3 was found in the developing heart, namely the outflow tract (oft), the peri- and myocardium ( $\mathrm{p}$, $\mathrm{m}$ ) as well as in the pericardial roof (r) and endocardium (e). (B,J-L) Sections through the eye showed a weak crip3 expression in the cornea epithelium (CE) at stage 33/34 (B) and in the ganglion cell layer (GCL) and lens (le) at stage 37/38 and 41, while the inner and outer nuclear layers (NL, ONL) and the retinal pigmented epithelium (RPE) were negative for crip3 (J-L). (M-N) At stage $41 \mathrm{crip} 3$ was expressed in the ceratohyal cartilage (CHC) and the branchial arches (ba). cg cement gland, hb hindbrain.

in the lens and the retina, in particular the ganglion cell layer, at stages 37/38 and 41 (green arrows in Fig. 8 E-H; Fig. 9 B,J-L).

Little is known about the embryonic crip3 expression in other organisms. Human CRIP3 could be detected in the fetal thymus, spleen, brain, heart, kidney, liver and lung partially in line with our observations (Casrouge et al., 2004). These limited findings make a comparison of the expression across species difficult.

As all three crip family members show a distinct expression pattern during early Xenopus development (Table 1), it would be interesting to examine their function during embryonic development by using knock-down approaches in future studies.

\section{Material and Methods}

\section{Xenopus laevis embryos}

Xenopusembryos were obtained, cultured according to standard protocols (Sive et al., 2000) and staged according to (Nieuwkoop and Faber, 1994).

\section{Cloning of Xenopus laevis crip1-3}

$X$. laevis cDNA fragments of $550 \mathrm{bp}$ (crip1; Acc. No. KP036486), 539 bp (crip2; Acc. No. KP036487) and 492 bp (crip3; Acc. No. KP036488) were cloned into the pSC-B vector (Stratagene, La Jolla, $\mathrm{Ca}$ ) by using cDNAs from stages 28 (crip1), 33 (crip3) or 42 (crip2) of $X$. laevis embryos. The primers were designed according to conserved sequence regions $(X$. laevis

\section{TABLE 1}

\section{SPATIAL EXPRESSION OF ALL THREE CRIP FAMILY MEMBERS DURING XENOPUS LAEVIS EMBRYOGENESIS}

\begin{tabular}{|c|c|c|c|c|c|c|c|c|}
\hline & \multicolumn{2}{|c|}{ Brain } & \multirow[b]{2}{*}{ Retina } & \multirow{2}{*}{$\begin{array}{l}\text { Cranial } \\
\text { nerves }\end{array}$} & \multirow{2}{*}{$\begin{array}{c}\text { Branchial } \\
\text { arches }\end{array}$} & \multirow{2}{*}{$\begin{array}{l}\text { Neural } \\
\text { tube }\end{array}$} & \multirow{2}{*}{$\begin{array}{c}\text { Cardiovasc. } \\
\text { system }\end{array}$} & \multirow{2}{*}{ Pronephros } \\
\hline & $\mathbf{m b}$ & hb & & & & & & \\
\hline crip1 & & & + & + & + & + & & + \\
\hline crip2 & + & + & + & & + & + & + & + \\
\hline crip3 & & & + & + & + & & + & + \\
\hline
\end{tabular}

$h b$ hindbrain; $m d$ midbrain.
crip1-a:NM_001093834.1; X. tropicaliscrip2:NM_001079267.1; X. tropicalis crip3:NM_001015811.1). Following cloning primers were used:crip1a_forw: 5'-CACCAGCAACATGCCCAAGTGT-3'; crip1a_rev: 5'-GTAAACATAATATACACCTGCTTGAAATGCTAT-3'; crip2_forw:5'-ATGGCTTCCAAGTGCCCCAAGTGT-3'; crip2_rev:5'-CCATAGCAAGGCTTGTGGCAGTAG-3'; crip3_forw:5'-CTTCGCAGAGAAAGTGAGCTCCTT-3'; crip3_rev:5'-CCGTAGCATGGAACATGGCAG-3'. The proof reading PfuUltra ${ }^{T M}$ II fusion HS DNA polymerase (Agilent Tech., Santa Clara, CA) was used for all PCR reactions. Amplification accuracies and inserts orientation were confirmed by sequencing. Sequences were deposited at NCBI with the accession numbers KP036486 (crip1), KP036487 (crip2) and KP036488 (crip3).

\section{Protein alignment and synteny analyses, phylogenetic tree}

The ClustalW2 program from the EMBL-EBI hompage was used for amino acid sequence alignment, homology calculation and generation of the phylogenetic tree. Following sequences were used: human CRIP1: NP_001302.1, mouse Crip1 NP_031789.1, rat Crip1: NP_001231796.1, X. tropicalis Crip1: NP_001165119.1, X. laevis Crip1-a: NP_001087303.1, zebrafish Crip1:NP_001153291.1, human CRIP2:NP_001303.1, mouse Crip2: NP_077185.1, ratCrip2:NP_071946.1, X. tropicalisCrip2:NP_001072735.1, zebrafish Crip2: NP_998662.2, human CRIP3: NP_996805.2, mouse Crip3 isofrom TLP-A: NP_858050.1 (homology) and isoform TLP-B: NP_444480.1 (phylogenesis), rat Crip3: NP_001102773.1, X. tropicalis Crip3: NP_001015811.1. NCBI GeneBank and Xenbase Genome Browser v7.1 were used for synteny analyses, genomic structure and chromosomal organisation. Human, mouse, rat, $X$. tropicalis and zebrafish crip1, crip2 and crip3 were compared.

\section{RNA isolation and RT-PCR assays}

To examine the temporal expression pattern of crip1-3, total RNA of Xenopus embryos at different developmental stages (stages 1 to 41 ) was isolated using the peq-GOLD RNApure kit (Peqlab, Erlangen, D). cDNA was generated using random primers and the SuperScript II reverse transcriptase (Invitrogen, Carlsbad, CA). RT-PCRs were performed using the Phire Hot Start II DNA polymerase (Thermo Scientific, Waltham, MA) and following primers:GAPDH_RT_forw:5'-GCCGTGTATGTGGTGGAATCT-3'; GAPDH_RT_rev:5'-AAGTTGTCGTTGATGACCTTTGC-3';Crip1_RT_forw: 5'-GGTATCCTCCCTGGGAAAAG-3'; Crip1_RT_rev: 5'-ATTTGCCT- 
TACTCGGCACAC-3'; Crip2_RT_for:5'-GCCCCAAGTGTGACAAGACT-3'; Crip2_RT_rev: 5'-GCTGGAAGCTTTGCTGAGAC-3'; Crip3_RT_forw: 5'-CTTCGCAGAGAAAGTGAGCTCCTT-3'; Crip3_RT_rev: 5'-CCGTAGCATGGAACATGGCAG-3'. Note that crip1 primers were designed using the previously published Xenopus laevissequence (Acc. No. NM_001093834.1) and therefore do not completely match with the sequence shown in Suppl. Fig. 1. Annealing temperatures were: gapdh: $55^{\circ} \mathrm{C}$; crip $1: 52^{\circ} \mathrm{C}$; crip2: $51^{\circ}$; crip3: $54^{\circ} \mathrm{C}$ and the product lengths were: gapdh: $230 \mathrm{bp}$; crip1: $366 \mathrm{bp}$; crip2: 332bp; crip3: $488 \mathrm{bp}$.

\section{Dot blot}

Dot blotting using Hybond- $\mathrm{N}^{+}$nucleic acid transfer membranes (GE Healthcare, Cleveland, Ohio) was done to test RNA probes for their specificity. $1 \mu \mathrm{g}$ of plasmid DNA of crip 1-3 was diluted in 2x SSC buffer, denatured, dot blotted and hybridized with crip1-3 digoxigenin-labeled antisense RNA probes according to the manufactures instruction (GE Healthcare, 9.5 protocol for dot blotting and 10.2 hybridization protocol). Blocking and staining of the blots with BM-Purple (Roche, Basel) was done according the WMISH protocol.

\section{Whole mount in situ hybridization (WMISH) and sectioning}

To investigate the spatio-temporal expression of crip1-3 digoxigeninlabeled antisense RNA probes were generated by in vitro transcription with either T7 or T3 RNA polymerase (Roche, Basel). WMISH analyses were performed according to established protocols (Hemmati-Brivanlou et al., 1990) using fixed Xenopus embryos at different developmental stages, which were subsequently stained with BM-Purple (Roche, Basel). For more detailed analyses of the gene expressions vibratome sections of $25 \mu \mathrm{m}$ thickness were performed as previously described (Guo et al., 2011).

\section{Acknowledgements}

Annemarie Hempel is a member of the International Graduate School in Molecular Medicine of Ulm University (GSC270). We thank especially Karin Botzenhart and Petra Dietmann for their technical support.

\section{References}

BACH, I. (2000). The LIM domain: regulation by association. Mech Dev 91: 5-17.

BIRKENMEIER, E.H. and GORDON, J.I. (1986). Developmental regulation of a gene that encodes a cysteine-rich intestinal protein and maps near the murine immunoglobulin heavy chain locus. Proc Natl Acad Sci USA83: 2516-2520.

CASROUGE, A., VEITIA, R., KIRCHNER, J., BEVAN, M.J. and KANELLOPOULOS, J. (2004). The human and mouse orthologous LIM-only proteins respectively encoded in chromosome 6 and 17 show a different expression pattern. Microbes Infect 6: 1063-1072.

CHUNG, Y.C., TSAI, Y.J., SHIU, T.Y., SUN, Y.Y., WANG, P.F. and CHEN, C.L. (2011). Screening large numbers of expression patterns of transcription factors in late stages of the mouse thymus. Gene Expr Patterns 11: 84-92.

DAVIS, B.A., BLANCHARD, R.K., LANNINGHAM-FOSTER, L. and COUSINS, R.J. (1998). Structural characterization of the rat cysteine-rich intestinal protein gene and overexpression of this LIM-only protein in transgenic mice. DNA Cell Biol 17: 1057-1064.

GUO, Y., CHRISTINE, K.S., CONLON, F., GESSERT, S. and KUHL, M. (2011). Expression analysis of epb4114a during Xenopus laevis embryogenesis. Dev Genes Evol 221: 113-119.

HALLQUIST, N.A., KHOO, C. and COUSINS, R.J. (1996). Lipopolysaccharide regulates cysteine-rich intestinal protein, a zinc-finger protein, in immune cells and plasma. $J$ Leukoc Biol 59: 172-177.

HEMMATI-BRIVANLOU, A., FRANK, D., BOLCE, M.E., BROWN, B.D., SIVE, H.L. and HARLAND, R.M. (1990). Localization of specific mRNAs in Xenopus embryos by whole-mount in situ hybridization. Development 110: 325-330.

HEMPE, J.M. and COUSINS, R.J. (1991). Cysteine-rich intestinal protein binds zinc during transmucosal zinc transport. Proc Natl Acad Sci USA88: 9671-9674.

HEMPE, J.M. and COUSINS, R.J. (1992). Cysteine-rich intestinal protein and intestinal metallothionein: an inverse relationship as a conceptual model for zinc absorption in rats. J Nutr 122: 89-95.

KARIM, M.A., OHTA, K., EGASHIRA, M., JINNO, Y., NIIKAWA, N., MATSUDA, I. and INDO, Y. (1996). Human ESP1/CRP2, a member of the LIM domain protein family: characterization of the cDNA and assignment of the gene locus to chromosome 14q32.3. Genomics 31: 167-176.

KHOO, C., HALLQUIST, N.A., SAMUELSON, D.A. and COUSINS, R.J. (1996) Differential expression of cysteine-rich intestinal protein in liver and intestine in CCl4-induced inflammation. Am J Physiol 270: G613-G618.

KIRCHNER, J., FORBUSH, K.A. and BEVAN, M.J. (2001). Identification and characterization of thymus LIM protein: targeted disruption reduces thymus cellularity. Mol Cell Biol 21: 8592-8604.

LANNINGHAM-FOSTER, L., GREEN, C.L., LANGKAMP-HENKEN, B., DAVIS, B.A NGUYEN, K.T., BENDER, B.S. and COUSINS, R.J. (2002). Overexpression of CRIP in transgenic mice alters cytokine patterns and the immune response. $A m$ $J$ Physiol Endocrinol Metab 282: E1197-E1203.

LEVENSON, C.W., SHAY, N.F., LEE-AMBROSE, L.M. and COUSINS, R.J. (1993). Regulation of cysteine-rich intestinal protein by dexamethasone in the neonatal rat. Proc Natl Acad Sci USA90: 712-715.

LIEBHABER, S.A., EMERY, J.G., URBANEK, M., WANG, X.K. and COOKE, N.E. (1990). Characterization of a human cDNA encoding a widely expressed and highly conserved cysteine-rich protein with an unusual zinc-finger motif. Nucleic Acids Res 18: 3871-3879.

NALIK, P., PANAYOTOVA-HEIERMANN, M. and PONGS, O. (1989). Characterization of an estradiol-stimulated mRNA in the brain of adult male rats. Mol Cell Endocrinol 62: 235-242.

NIEUWKOOP, P.D. and FABER, J. (1994). Normal table of Xenopus laevis (Daudin): a systematical and chronological survey of the development from the fertilized egg till the end of metamorphosis. Garland Pub., New York.

OKANO, I., YAMAMOTO, T., KAJI, A., KIMURA, T., MIZUNO, K. and NAKAMURA, T. (1993). Cloning of CRP2, a novel member of the cysteine-rich protein family with two repeats of an unusual LIM/double zinc-finger motif. FEBS Lett 333: 51-55.

SIVE, H.L., GRAINGER, R.M. and HARLAND, R.M. (2000). Early development of Xenopus laevis: a laboratory manual. Cold Spring Harbor Laboratory Press, Cold Spring Harbor, N.Y.

SUN, X., ZHANG, R., LIN, X. and XU, X. (2008). Wnt3a regulates the development of cardiac neural crest cells by modulating expression of cysteine-rich intestinal protein 2 in rhombomere 6. Circ Res 102: 831-839.

TANABE, C., HOTODA, N., SASAGAWA, N., FUTAI, E., KOMANO, H. and ISHIURA, S. (2010). ADAM19 autolysis is activated by LPS and promotes non-classical secretion of cysteine-rich protein 2. Biochem Biophys Res Commun 396: 927-932.

TSUI, S.K., YAM, N.Y., LEE, C.Y. and WAYE, M.M. (1994). Isolation and characterization of a cDNA that codes for a LIM-containing protein which is developmentally regulated in heart. Biochem Biophys Res Commun 205: 497-505.

VAN HAM, M., CROES, H., SCHEPENS, J., FRANSEN, J., WIERINGA, B. and HENDRIKS, W. (2003). Cloning and characterization of mCRIP2, a mouse LIM-only protein that interacts with PDZ domain IV of PTP-BL. Genes Cells 8: 631-644.

WANG, W., ZHANG, L.F., GUI, Y.H. and SONG, H.Y. (2013). Retinol dehydrogenase, $\mathrm{RDH} 11$, is essential for the heart development and cardiac performance in zebrafish. Chin Med J (Engl) 126: 722-728.

WANG, X., LEE, G., LIEBHABER, S.A. and COOKE, N.E. (1992). Human cysteinerich protein. A member of the LIM/double-finger family displaying coordinate serum induction with c-myc. J Biol Chem 267: 9176-9184.

WEI, T.C., LIN, H.Y., LU, C.C., CHEN, C.M. and YOU, L.R. (2011). Expression of Crip2, a LIM-domain-only protein, in the mouse cardiovascular system under physiological and pathological conditions. Gene Expr Patterns 11: 384-394.

WIESE, C.B., IRELAND, S., FLEMING, N.L., YU, J., VALERIUS, M.T., GEORGAS, K., CHIU, H.S., BRENNAN, J., ARMSTRONG, J., LITTLE, M.H. et al., (2012). A genome-wide screen to identify transcription factors expressed in pelvic Ganglia of the lower urinary tract. Front Neurosci 6: 130.

YU, T.S., MOCTEZUMA-ANAYA, M., KUBO, A., KELLER, G. and ROBERTSON, S. (2002). The heart LIM protein gene (HIp), expressed in the developing and adult heart, defines a new tissue-specific LIM-only protein family. Mech Dev116: 187-192.

ZHANG, L., HOFFMAN, J.A. and RUOSLAHTI, E. (2005). Molecular profiling of heart endothelial cells. Circulation 112: 1601-1611. 


\section{Further Related Reading, published previously in the Int. J. Dev. Biol.}

Sexual dimorphism of AMH, DMRT1 and RSPO1 localization in the developing gonads of six anuran species

Rafal P. Piprek, Anna Pecio, Katarzyna Laskowska-Kaszub,Jacek Z. Kubiak and Jacek M. Szymura

Int. J. Dev. Biol. (2013) 57: 891-895

Dual embryonic origin of the hyobranchial apparatus in the Mexican axolotl (Ambystoma mexicanum)

Asya Davidian and Yegor Malashichev

Int. J. Dev. Biol. (2013) 57: 821-828

Clonal analyses in the anterior pre-placodal region: implications for the early lineage bias of placodal progenitors

Sujata Bhattacharyya and Marianne E. Bronner

Int. J. Dev. Biol. (2013) 57: 753-757

Amphibian interorder nuclear transfer embryos reveal conserved embryonic gene transcription, but deficient DNA replication or chromosome segregation

Patrick Narbonne and John B. Gurdon

Int. J. Dev. Biol. (2012) 56: 975-986

Origins of $\mathrm{Cdx} 1$ regulatory elements suggest roles in vertebrate evolution

Stephen J. Gaunt and Yu-Lee Paul

Int. J. Dev. Biol. (2011) 55: 93-98

Reptile scale paradigm: Evo-Devo, pattern formation and regeneration

Cheng Chang, Ping Wu, Ruth E. Baker, Philip K. Maini, Lorenzo Alibardi and Cheng-Ming Chuong

Int. J. Dev. Biol. (2009) 53: 813-826

Proteomics analysis of regenerating amphibian limbs: changes during the onset of regeneration

Michael W. King, Anton W. Neff and Anthony L. Mescher

Int. J. Dev. Biol. (2009) 53: 955-969

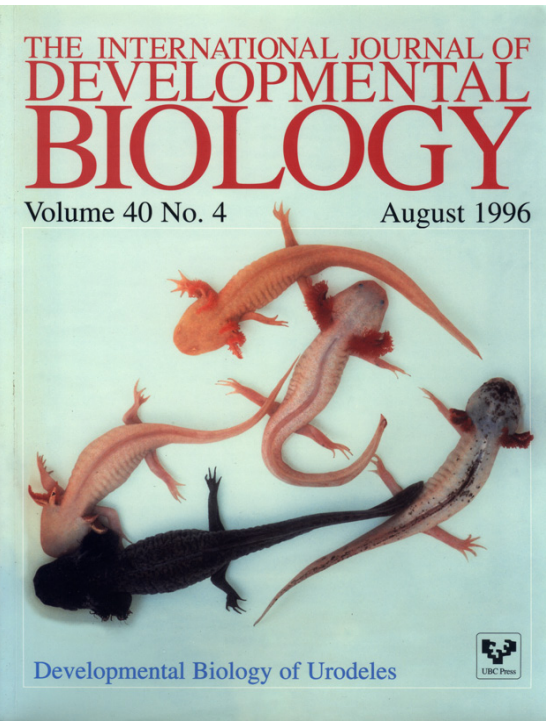

5 yr ISI Impact Factor $(2013)=2.879$
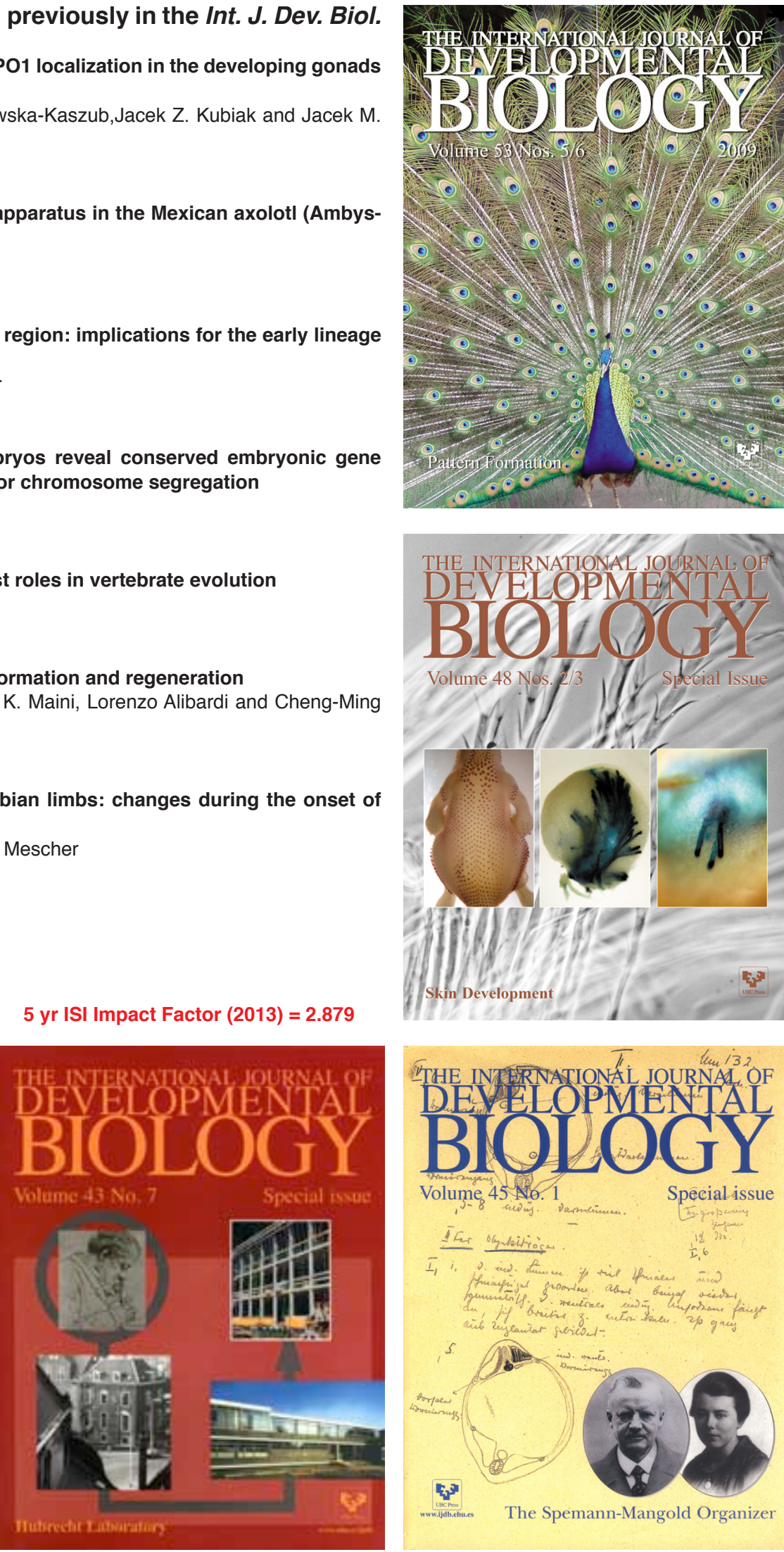

Volume 45 No. 1

Special-issue

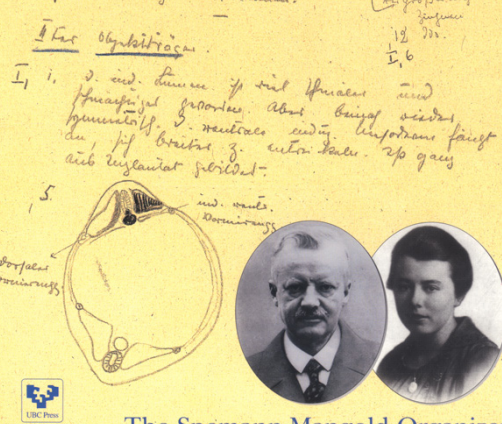

The Spemann-Mangold Organizer 